\title{
El proyecto_re-HABITAR incorpora el Movimiento Moderno a la metodología de la conservación patrimonial
}

El proyecto_re-HABITAR, coordinado por el Instituto Andaluz del Patrimonio Histórico (IAPH), tiene como objetivo conocer mejor una parte del patrimonio residencial, especialmente el vinculado a las etapas de mayor crecimiento de las ciudades en el s. XX. La iniciativa_re-HABITAR está orientada al conocimiento de las arquitecturas reconocidas en el Movimiento Moderno, en concreto de la vivienda colectiva y social de mediados del siglo pasado, con el fin de desarrollar nuevas maneras de relacionarnos con esta herencia y conservar sus valores patrimoniales. Distintas instituciones de investigación, patrimoniales o tecnológicas, aúnan esfuerzos en el desarrollo de unos principios que integren el Movimiento Moderno de arquitectura en la metodología de intervención y conservación practicadas desde el IAPH hace más de 25 años.

José Luis Gómez Villa | Centro de Intervención del IAPH

URL de la contribución <www.iaph.es/revistaph/index.php/revistaph/article/view/4121>

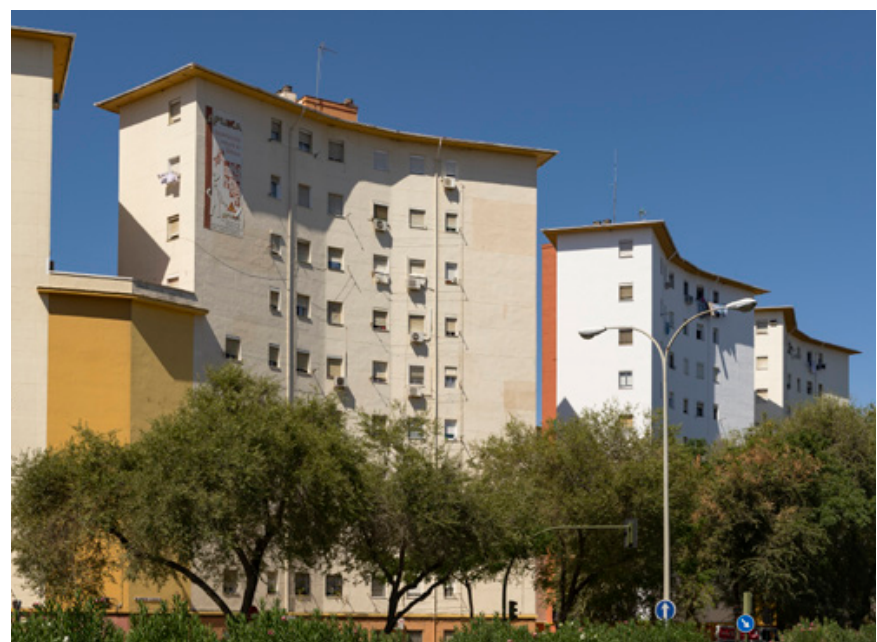

Conjunto Residencial Nuestra Señora del Carmen | foto Fondo Gráfico IAPH (José Manuel Santos)

Partiendo del liderazgo del IAPH, el proyecto se nutre de la especialización de otros organismos dedicados a la protección del patrimonio del Movimiento Moderno, como Docomomo Ibérico, así como del conocimiento y especialización de destacados equipos de investigación de la Universidad de Sevilla, procedentes del Instituto Universitario de Arquitectura y Ciencias de la Construcción de la Escuela de Arquitectura y del Departamento de Ingeniería Electrónica de la Escuela
Superior de Ingenieros de Sevilla, o especialistas del ámbito de la historia y la arquitectura. Como valor añadido, el proyecto plantea la participación activa de la comunidad vecinal, como agente determinante en el aprecio y en el contraste de la presencia de valores patrimoniales en este tipo de arquitectura.

El objeto de estudio que sirve como modelo es el conjunto residencial Nuestra Señora del Carmen, un proyecto de vivienda social construido entre 1955 y 1958 y diseñado por el arquitecto Luis Recasens Queipo de Llano, autor también de Los Diez Mandamientos, cuyo objetivo fue reducir el déficit de vivienda en la ciudad de Sevilla. Sus características le confieren rango de operación urbana, por su carácter de conjunto y su articulación con respecto a la trama de la ciudad. Está compuesto por 52 bloques con más de 600 viviendas que organizan un singular conjunto de espacios públicos. Su situación en la ciudad y sus características arquitectónicas están íntimamente vinculadas a su expresión social y cultural.

_re-HABITAR se plantea como un trabajo de cooperación de distintos agentes con un enfoque transdisciplinar. El trabajo realizado por el equipo motor y por los distintos equipos de investigación y trabajo permitirá dar 


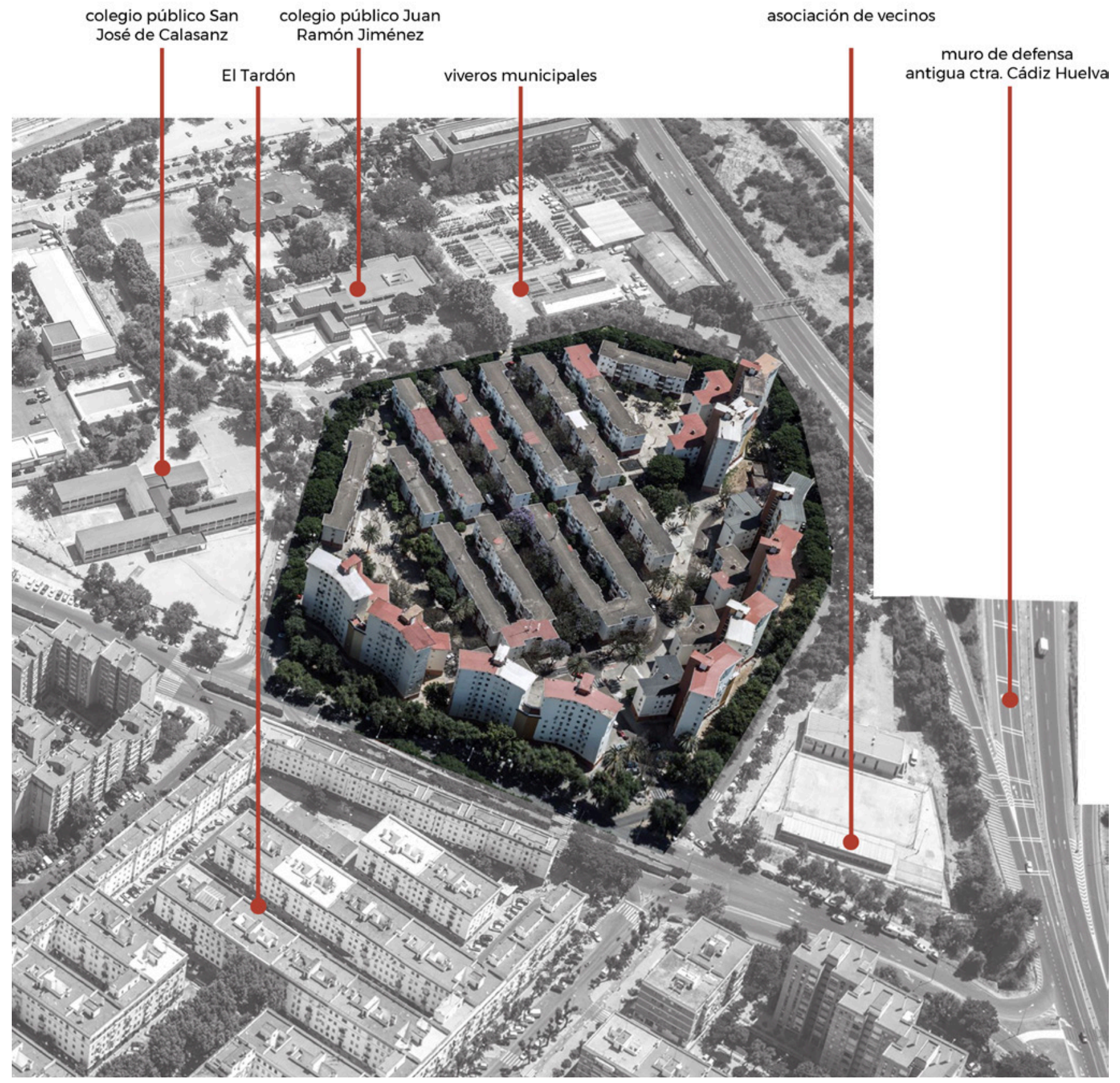

Barriada del Carmen y entorno | infografía Antonio Alanís Arroyo 
forma a una reflexión amplia considerando cuestiones patrimoniales, históricas, sociológicas, antropológicas, tecnológicas, normativas, constructivas y materiales. La comunidad de vecinos de El Carmen juega un papel fundamental en la configuración de esta forma de trabajar. Su participación será de vital importancia para la caracterización del conjunto residencial.

La misión del proyecto_re-HABITAR es definir y compartir sobre la vivienda social del Movimiento Moderno maneras de registro de sus valores patrimoniales y garantizar su persistencia, implicando a la ciudadanía. Desde una comprensión transversal, se plantea un trabajo que haga partícipes a los vecinos de las decisiones y las maneras de cuidar este patrimonio, convirtiéndolos en parte activa e indispensable del proceso.

Con su carácter inclusivo, _re-HABITAR pretende abarcar un amplio alcance, aglutinando distintas voces y perspectivas para construir un relato desde la diversidad. En la definición del proyecto de investigación, la comunicación se convertía en un aspecto crucial. De acuerdo a esta premisa, se ha potenciado la presencia digital del proyecto en las redes sociales y en los medios de comunicación. Destaca el desarrollo de una plataforma web, http://www.iaph.es/rehabitar, que se concibe como el nodo central que permita conectar los distintos aspectos del proyecto, la experiencia offline con los contenidos digitales y que recoja la conversación social al respecto. Esta plataforma incorpora un espacio para que las distintas voces participantes puedan dar forma a un relato transversal en el que la relatoría vecinal tendrá un lugar destacado.

Conocer la materialidad o la evolución de esta arquitectura desde sus orígenes a nuestros días se presenta como tradicional punto de arranque en la caracterización patrimonial, pero carentes de sentido en este caso sin el peso social de un patrimonio habitado que tiene unas características propias que condicionarán criterios de conservación o actuación. El proyecto científico trasciende el límite entre disciplinas y apuesta por el compromiso social para favorecer una reflexión sobre la ciudad contemporánea a través de la cooperación ineludible con las personas que la habitan.

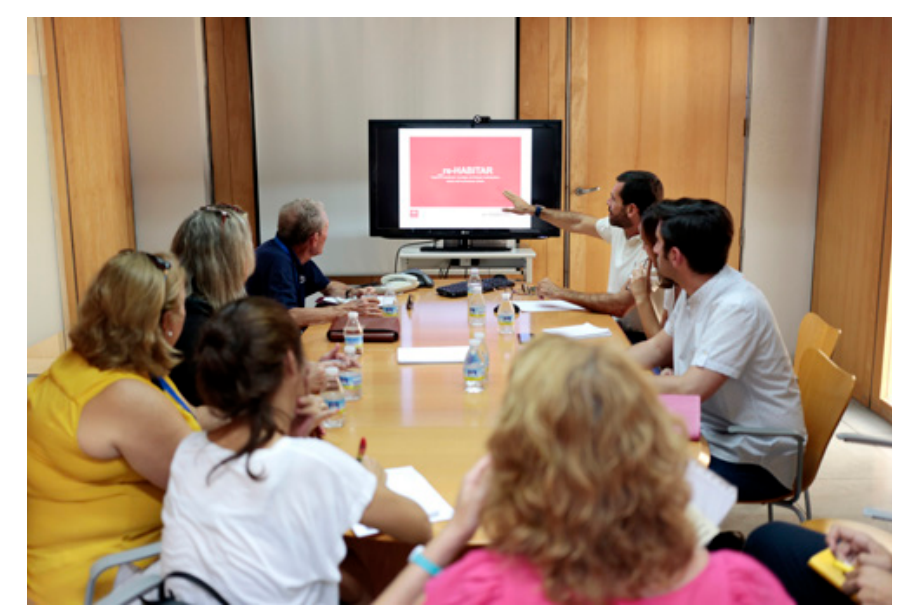

Encuentro entre vecinos e investigadores del proyecto_re-HABITAR, 2017

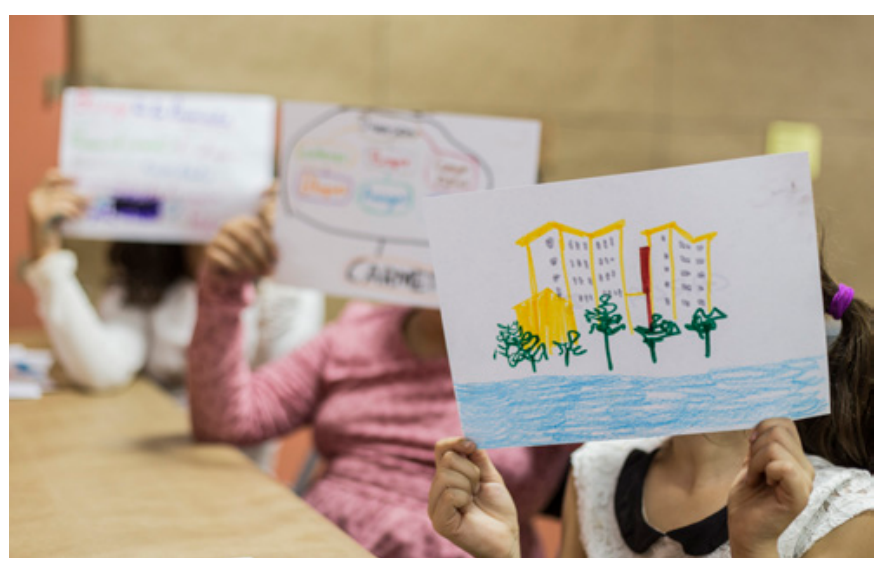

Taller Participativo Infantil_re-HABITAR | fotos Julia Córdoba

El proyecto de investigación y aplicación del conocimiento _re-HABITAR fue una apuesta iniciada por el IAPH en 2012, incentivada por la Consejería de Economía y Conocimiento de la Junta de Andalucía en 2016. Los trabajos de campo y las investigaciones se iniciaron en el primer trimestre de 2017, mientras que los resultados científicos y metodológicos se conocerán a lo largo de 2018, con la presentación de los mismos en un seminario sobre el valor patrimonial de la arquitectura residencial del Movimiento Moderno y una publicación monográfica. El desarrollo de estos trabajos se caracteriza por el compromiso con la innovación, la orientación al servicio público y la participación social. 